\title{
Integrating the Visual Design Discipline with Information Systems Research and Practice
}

\author{
Daniel A. Peak, Victor R. Prybutok, \\ $Y u$ "Andy" Wu, and Chenyan Xu \\ University of North Texas, Denton, TX, USA \\ daniel.peak@unt.edu; victor.prytutok@unt.edu; \\ andy.wu@unt.edu; chenyan.xu@unt.edu
}

\begin{abstract}
This paper examines the relationship between visual design and information systems (IS) design and describes how IS theory and practice has viewed visual design (an aesthetic discipline) from a positivist perspective. First, we present a rationale for the current view of aesthetics from the positivistic IS discipline. After tracing the philosophical development of aesthetics and its associated disciplines, we then follow the more recent development of positivism and the scientific method. Based on assertions by both philosophers and IS researchers, we examine the differing perspectives of the aesthetic and positivist disciplines from an IS vantage point. We propose that visual aesthetic design be integrated with IS theory and describe the benefits that are potentially gained from this transdisciplinary approach.
\end{abstract}

Keywords: Framework, paradigm, bridge, pluralism, aesthetics, positivism, visual design, visual systems design

\section{Introduction}

The process of creating a visual interface involves both art and science, a unified process that requires visual design theory and process and functional systems development knowledge. (Krug, 2006; Lawrence, Tavakol, \& Soyhela, 2007; Mullet \& Sano, 1995; Norman, 1998). The desired balance of appearance and functionality is determined with and by the user. Successful aestheticfunctional interfaces exhibit characteristics that are evidenced by mature commercial products (Norman, 2002b; Norman, 2004). According to Norman (1998) computer technology, including information systems, generally does not exhibit mature product characteristics because computer systems are frequently difficult to use. A key to diminishing the usability shortcomings of computer technology is to increase the friendliness of the interface (Krug, 2006).

From the informing science perspective, an information system consists of a set of interrelated

Material published as part of this publication, either on-line or in print, is copyrighted by the Informing Science Institute. Permission to make digital or paper copy of part or all of these works for personal or classroom use is granted without fee provided that the copies are not made or distributed for profit or commercial advantage AND that copies 1) bear this notice in full and 2) give the full citation on the first page. It is permissible to abstract these works so long as credit is given. To copy in all other cases or to republish or to post on a server or to redistribute to lists requires specific permission and payment of a fee. Contact HPublisher@InformingScience.orgH to request redistribution permission. tasks, technology, structure, and people (Gill \& Bhattacherjee, 2007). Therefore, while technology stands at the core of the informing science framework, issues regarding "biological and psychological issues in how clients attend, perceive, and act on information provided" (Cohen, 2009, p. 6) must be resolved. While friendly interfaces enhance the user experience, a poorly-designed interface, can provoke multi-faceted negative 
impacts on system users (Hassenzahl, 2004). First, flawed interfaces are detrimental to human cognition. Because interfaces guide the decision processes of computer users, interfaces have an enormous influence on the economic, physical, and mental well-being of virtually all users (Hartmann, Sutcliffe, \& De Angeli, 2008). Secondly, flawed interfaces can impair affective response. In her work, Zhang (2009) contended that, in the context of information and communication technology (ICT), aesthetic perception influences human behavior through a sequential aesthetics-affect-emotion-action chain. An impaired or garbled affective response can adversely affect system user behavior. Thirdly, a poorly-designed interface can contravene human nature. People are genetically designed to appreciate beauty (Kogan, 1994, 1997). It follows that a system with an aesthetically pleasing appearance improves user moods and overall system impression, while for unpleasing appearance the converse is true (Tractinsky, Katz, \& Ikar, 2000).

In addition to the forgoing client issues, Cohen's informing science framework also entails "the decision-making environment...", "issues involving the media for communicating information", and "error, bias, misinformation, and disinformation in informing systems" $(2009$, p. 6). For the system user, the system interface emerges as part of the user environment. Aesthetics values aside, visualization can serve as an effective medium to convey information. Visual techniques, supported by effectively-applied aesthetic design principles, enhance the processing of information to improve comprehension, memory, and inference (Agrawala, Li, \& Berthouzoz, 2011).

To date, a handful of IS theories and research has devoted attention to aesthetic visual design and its potential personal and commercial advantages for information systems products (Hassenzahl, 2004; Hassenzahl, Schöbel, \& Trautmann, 2008; Lavie \& Tractinsky, 2004; Tractinsky \& Rao, 2001). Conversely, it is not surprising that many systems developers create visual systems of inconsistent quality because they lack knowledge, skills, and tools (Lavie \& Tractinsky, 2004; Tractinsky, 2006; Tractinsky, Cokhavia, Kirschenbauma, \& Sharfib, 2006). Current development practice, including web-based systems, is affected by this inconsistency, where theory and methods focus on the system and its technology but devote insufficient attention to the user and the interface (Krug, 2006). For example, when IS developers perform web-based design, they are using aesthetic characteristics. Inevitably, the website user will perform a visual assessment of the developers' work. As evidenced by the absence of same from the IS literature, developers create websites without a framework, a typology, or a systematic understanding of aesthetic variables and their effects (D. Edwards, 2003; Lavie \& Tractinsky, 2004; Tractinsky, 2004; Tractinsky et al., 2006). We believe such a deficit in web-based research and development can be remedied by integrating the theory and skills of visual aesthetic design with IS web-based systems.

It is a difficult task to harmonize the ambiguous and subjective aesthetic design theory with the precise and objective IS systems theory (De Angeli, Sutcliffe, \& Hartmann, 2006). This is partially the result of the independent evolution of the visual design and IS professions. As system developers struggle with this disconnect, they are observed to cope with aesthetics issues by outsourcing to visual designers (Lowe \& Eklund, 2001), by relying on visually-inadequate "gutfeelings" and "educated guesses" (Noblet, 1993), or by employing predicted visual "trends" and "hunches" to execute a visual design themselves (Liu, 2003). These ancillary approaches indicate that IS developers are unfamiliar with established visual design practice (Norman, 2004). Such approaches may also manifest a reluctance to embrace visual design theory because the IS discipline is more accustomed to attacking "hard" problems than "soft" issues such as aesthetics.

In sum, to better inform IS developers, transdisciplinary research is needed to span the gap between the paradigmatically dissimilar areas of aesthetics and IS. However, this is changing and a growing body of IS literature examines the visual issues involved with web design (Cyr, Head, \& Lario, 2010; Cyr, Head, Larios, \& Bing, 2009). This paper takes the next suggested step toward integrating the two areas (Peak, Gibson, \& Prybutok, in press) and posits a transdisciplinary re- 
search approach. Toward that end, we pose two questions. First, why would a theoretical separation in such an important area exist in the first place? Second, how can we close the gap between these two fields?

To answer these questions in the spirit of informing science, we first review recent IS research that deals with visual design to illustrate the necessity of embracing the aesthetics known to visual designers. We then describe and present a rationale for the current under-exploration of aesthetics from positivism in the IS discipline. While aesthetics is referenced in the IS literature, the IS usage of the term is frequently different from the context in which it is used by visual designers. We trace the genesis of aesthetics and its disciplines from the ancient Greeks to the present, and then follow the more recent development of positivism and the scientific method. Based on assertions by both philosophers and IS researchers, we demonstrate the separation of the two paradigms and offer as an explanation positivist lensing. Finally, we propose that IS researchers and systems developers integrate the disciplines of visual aesthetic design and IS in both research and practice.

\section{Visual System Design and Informing Science}

We regard with enthusiasm the recent interest of IS research in visual design. For example, research indicates that effective visual design of e-commerce websites increases the value of the sites and evokes positive emotions for users, which can be accomplished by human images (Cyr et al., 2009). Color appeal, elicited by choice of colors, affects trust or satisfaction of online shoppers and has the potential to enhance e-loyalty (Cyr et al., 2010). Other research observed that socially rich pictures enable a sense of social presence related to users' experience of websites (Hassanein \& Head, 2007). Website complexity, as a function of site elements like amount of text, animation, and graphics, webpage consistency, clarity of hyperlinks, and so forth is central to the visitors' experiences at sites (Nadkarni \& Gupta, 2007). These studies aspire to embrace aesthetics into the conventional IS systems development paradigm, thereby broadening the predominant focus beyond usability and instrumental human needs.

A careful review of this stream of research reveals two relevant issues. First, in the inquiry of how visual design works, the scale ultimately leans to the IS plane where classic IS constructs like perceived usefulness, satisfaction, and trust are key. However, the IS constructs fail to adequately describe how to implement the visual elements. While we gain further understanding of how visual design impacts user perceptions and behaviors, little is documented about how to design, configure, and optimize a "visual artifact" (e.g., human images, colors). For example, a few studies start with a single or a combination of finished visual artifact(s), say, two human images - with and without facial characteristics (Cyr et al., 2009). Therefore, while the research proves that a human image with facial characteristics engenders a higher level of online trust, questions like how to manipulate the layout, focus, or contrast of that image to elicit the optimized effects still remain unexplored. In a sense, this stream of research represents the disciplinary "laser research" (Cohen, 2009), providing more depth than breadth. While it is not our intent to challenge this important first line of important visual laser research, we do believe that a transdisciplinary "lantern research" approach (Cohen, 2009) for "enlightening interrelationships of nearby objects" (p. 2) offers the potential to enhance both disciplines. Objects, in this case, refer to factors regarding visual system design. Stated in another way, visual design principles from the aesthetics plane should be integrated into current IS design theories and practice.

Second, the forgoing research provides an important first step toward integrating visual system design but touches upon only a small of portion of aesthetic concepts such as clarity, color, complexity, focus, and harmony. In fact, the visual design discipline boasts of dozens of visual characteristics, constructs, variables, and sub-variables (Peak et al., in press). From the IS perspective, aesthetics is conceptualized as a multi-dimensional yet abridged positivist construct, for ex- 
ample containing non-visual design characteristics such as pretty, colorful, and bright (Cyr et al., 2009) or employing non-visual design descriptors such as simplicity, diversity, colorfulness, and craftsmanship (Moshagen \& Thielsch, 2010). The reality of visual design is itself complex with many different elements, all of which are true but each of which is only part of the whole truth (Cohen, 2009). We believe that the aforementioned IS works featuring the positivist approach can provide guidance to inform IS developer clients. However, to get a richer and more informed picture of visual system design, we can benefit from embracing additional works, precepts, and philosophies from the aesthetic perspective.

\section{Aesthetics and Its Importance to Systems Design}

Aesthetics is the theory and study of beauty, which in one form or another is experienced by all individuals and all cultures (Hofstadter \& Kuhns, 1976; Runes, 1977; Sheppard, 1987). Although aesthetics embraces both art and design, these two related areas target different outcomes (D. Edwards, 2003). Art is the aesthetic discipline that deals with the creation of beauty to achieve emotion, while visual design is an artistic, applied discipline that employs aesthetic theory and visual techniques to complete a planned product, often for a paying client (Mullet \& Sano, 1995; Rand, 1993). In contrast with the recent advent of the IS discipline, aesthetic concepts in the Western cultures are ancient, having originated with the Greeks more than 2,400 years ago (Hofstadter \& Kuhns, 1976).

\section{Classical Aesthetics and the Concept of the Universal Ideal as Related to Information Systems}

Plato (circa $428 \mathrm{BC}-347 \mathrm{BC}$ ) is commonly viewed as the founder of philosophical aesthetics (Hofstadter \& Kuhns, 1976; Russell, 1972; Sheppard, 1987). The genesis of the word "information" can be traced to Plato and his colleagues; it means taking the "form" of something into the mind, where that form then can shape how the mind thinks (Hofstadter \& Kuhns, 1976). In his theory of forms, Plato suggested that there exist an infinite number of ideal, but nonetheless real, forms, of which physical things are imperfect copies. Plato emphasized that the maker who copies the ideal (or "universal") can only judge the quality of the material copy by comparing it with the ideal. To make a beautiful thing, knowing must precede the making, so that one must grasp in advance its ideal form, its purpose, and its limitations (Hofstadter \& Kuhns, 1976; Russell, 1972; Sheppard, 1987). These seminal concepts are now essential tenets of such diverse subjects as contemporary visual design, information systems, and planning. Ever since the rediscovery and circulation of Plato's aesthetic ideas at the outset of the Italian Renaissance (1350-1750), his ideas have guided the aesthetic decision-making of many artists and visual designers (Rand, 1993; Sheppard, 1987). However, despite having origins conceptually interrelated with information and planning, aesthetics has established few inroads with the current design processes of visual information systems, including the processes of creating websites.

Aesthetic beauty is an elemental characteristic of people and societies (Beryls \& Lopes, 2006). According to Kogan $(1997,1994)$, the appreciation of beauty is a pre-established genetic attribute that fulfills a basic, biological function. "We're designed to care about looks, even though looks aren't earned and reveal nothing about character" (Cowley, 2000, p. 193). Research indicates that attractive individuals or beautiful things are assumed to possess other desirable characteristics. Individuals or things that are aesthetically pleasing in appearance receive preference and are expected to receive preference (Dion, Berscheid, \& Walster, 1972) Personal benefits of being beautiful include higher wages (French, 2002; Hamermesh \& Parker, 2005), more attention from instructors (Babad, Inbar, \& Rosenthal, 1982), and better teaching evaluations from students (Hamermesh \& Parker, 2005). Product aesthetics is often the only differentiating factor in crowded or mature markets (Artacho-Ramirez, Diego-Mas, \& Alcaide-Marzal, 2008; Postrel, 
2002; Tractinsky, 2006), while customers expect attractive things to work better regardless of their real performance (Norman, 2002a). In addition, a customer's positive response to the design's aesthetics may improve his or her mood and overall impression of the system (Tractinsky et al., 2000). With these positivistically-obtained results, science is only confirming deep-seated, centuries-old concepts that are basic to visual aesthetics and to visual aesthetic perceptions.

\section{Modern Aesthetics and the Concepts of Taste, Experience, and Pleasure as Related to Information Systems}

Although some philosophers persistently tie aesthetics with Platonic idealism (Graham, 2003), others such as David Hume (1711-1776) rejected Platonism and espoused empiricism, which views aesthetics as a normative, value-based system. In this departure from aesthetic idealism, Humian thought maintains that a universal ideal does not exist and that human minds are not divinely informed (Kolakowski, 1968) All human knowledge is derived from individual and collective abilities to interpret and analyze sensory experience. Thus, Hume argued that no ideal form is necessary or even possible, so no normative model is necessary. In other words, there is no ideal cat but merely human judgment of what is a beautiful cat (Russell, 1972). The quality of judgment is conditioned empirically by experience with cats.

A contemporary of Hume, Alexander Baumgarten (1714-1782) developed an analogous, evaluative view of art that redefined aesthetic judgment to mean "taste": judgment wholly dependent on the individual's aesthetic sensibilities and capacity to appreciate beauty (Graham, 2003, p. 246). Aesthetic judgment (taste) can be guided either by principles and rules (objective or informed taste) or by personal preference (subjective taste). Baumgarten's approach further departed from the traditional Platonic intellectual judgment of ideal beauty and replaced it with sensual judgment of material things, transforming the concept of beauty from supreme perfection into hedonistic pleasure (Graham, 2003; Sheppard, 1987). Thus, Hume, Baumgarten, and their like-minded contemporaries gave rise to the modern, hedonic, view of art and beauty, where all things can be evaluated based on their ability to elicit sensory pleasure and assigned a material value based on the amount of pleasure they produce. This hedonic view of aesthetics does not resemble classical aesthetics. Hedonism is decried by some who maintain that it elevates personal preference to preeminence, overwhelming order with chaos (Schaeffer, 1976). We infer that the Greeks would have regarded modern aesthetics as ignoble or depraved. Nevertheless, the contemporary concepts of pleasing appearance, user satisfaction, and system value originate with Hume and Baumgarten (Heath, 2008; Holbrook \& Zirlin, 1985).

Gustav Fechner (1860-1912), an early German psychologist who pioneered experimental aesthetics, developed methods for measuring sensory thresholds between physical stimuli and psychological responses (Fechner, 1876). Heavily influenced by his own interest in contemporary artrelated trends, Fechner studied observer responses to artwork. He varied visual stimuli from simple, elemental displays to more complex displays to investigate which characteristics of art provided pleasure or displeasure (Liu, 2003). Fechner's incipient experimentation was advanced by researchers who further developed the notions of visual stimuli that can affect an individual's aesthetic response (Birkoff, 1933; Fransworth, 1932; Granger, 1955). Berlyne (1974) proposed that the pleasure in viewing a stimulus at first increases and then declines once visual complexity exceeds an optimal level. He contended that aesthetic response is more than a sum of stimuli, but that visual aesthetic enjoyment and pleasure are much more complex phenomena than previously thought.

Building on this work and also reinforcing Humian concepts of sensory aesthetic experience, Martindale and Moore (1988) found that priming - an implicit memory effect where exposure to a stimulus influences subsequent responses to a later stimulus - has an effect on user preference for colors. Previous exposure to color stimuli affected the viewer's response to additional color 
stimuli, suggesting that hedonic response is conditioned by the visual experience of the viewer. Reber, Schwarz, and Winkielman (2004) extended this inquiry, suggesting that aesthetic beauty is established in the cognitive processing experiences of the perceiver, which are partially a function of stimulus properties. They observed that the more fluently (easily) viewers process a visual object, the more positive their aesthetic response.

Although it has received little attention in the IS literature, aesthetics (taste) and pleasure (hedonics), as defined by contemporary usage, is an emerging topic in computer interface design and the Human-Computer Interaction (HCI) literatures. Recent research that shows that the aesthetics of visual interfaces, specifically, web-based interfaces, is a strong determinant of users' satisfaction and pleasure (Lavie \& Tractinsky, 2004). Others found that pleasure plays an important role in aesthetic judgment of visual interfaces (Betz, Crockett, Davis, \& Sparacino, 2004). Heinrich (2007) discusses the idealized concept of aesthetic beauty in interactive interfaces, but found these aesthetic beauty concepts difficult to measure and evaluate. Instead, he advocates adopting pleasure as a primary determinant of a successful interface. Petersen, Iversen, Krogh, and Ludvigsen (2004) observed that a main objective in the design of interactive computer interfaces is to stimulate user emotion. "The interaction ideal pursued as part of this 'emotion locomotion' is to design for pleasure and attraction (Shusterman, 1992, p. 270). Interfaces should be smart, seductive, rewarding, tempting, even moody, and thereby exhilarating to use (Petersen et al., 2004). This view was echoed in another study, where "participants preferred an interface evaluated as more attractive on the expressive aesthetics dimension (a concept strongly related to engagement and fun) despite an acknowledged inferior usability" (De Angeli et al., 2006, p. 276). The authors noted that their finding was consistent with other current research in web-based interfaces. Aesthetics is also emerging as design evaluation criteria. Gill and Hevner (2011) proposed a fitness-utility model for design science research, stressing on fitness to be the goal of design science. Within the new model, the authors proposed new design guidelines to evaluate the fitness, the choice of aesthetics elements, and the elegance of the design. Summarizing, even though the abilities of visual designers and IS professionals are both necessary to produce visual systems, disharmony still exists due to conceptual differences between the subjective approaches of the aesthetic disciplines (e.g., visual design) and the contrasting objective approaches of the positivistic disciplines (e.g., information technology and IS). We attribute the awkward relationship of positivism with aesthetics, in part, to the task and research approach differences between the two disciplines.

\section{Positivism and the Scarcity of Aesthetics in IS Research}

Positivism, the philosophy of science, was developed by August Comte (1798-1857) specifically to advance beyond subjective, imprecise notions. It sought to achieve a process that produces objective, rigorous, and testable theory. Comte's positivism directly rebutted the theology and metaphysics of the time (Runes, 1977) and maintained that the highest form of knowledge is knowledge derived from sensory phenomena and achieved by experience. By the beginning of the $20^{\text {th }}$ century, positivism had matured into a stricter scientific form called logical positivism, which emphasizes the now-familiar scientific attitudes, cooperative research, intersubjectivity, and the unity of science (Runes, 1977). In this paper, we refer to logical positivism simply as "positivism." The cornerstone of positivism is its rigorous method of systematic inquiry called "the scientific method."

Positivism is a guiding force in the information technology disciplines. "Most of the research in the field of Information Systems appears to be guided by one set of philosophical assumptions -those of positivism" (Goles \& Hirschheim, 2000, p. 249). While positivism is considered a defining strength of IS research, the authors caution that "such paradigm unity could prove problematic as it might stymie alternative conceptions of problems in the IS field (p. 249)." A decade 
after their observation, a largely monistic condition continues in the IS disciplines, with the vast majority of IS research being positivist-oriented and very little dealing with aesthetics

(Tractinsky, 2006). The emphasis of IS literature is predominantly functional, consistent with the functional heritage and youthfulness of the IS discipline. Another plausible reason is the focus on the IS disciplinary core. Sidorova, Evangelopoulos, Valacich, and Ramakrishnan (2008) found IS research to consistently focus on a core of topics that do not include aesthetics. Our reprocessing of the same data finds only three articles that mention "aesthetics," but none of these address visual aesthetic design. Although visual interfaces are important to IS systems users, the IS research literature exhibits exclusionary tendencies toward aesthetics. On the other hand, the same literature still includes numerous non-aesthetic disciplines that play a role in systems, reaching out to disciplines that are likewise positivistic, e.g., the behavioral sciences (psychology, sociology, and decision science), management, engineering, and computer science.

The challenge of positivism to embrace competing paradigms is well-documented (Gioia \& Pitre, 1990; Goles \& Hirschheim, 2000; Hofstadter \& Kuhns, 1976; Kuhn, 1970; Runes, 1977) as is IS' anchoring to positivism (Goles \& Hirschheim, 2000; Hallnas \& Redstrom, 2002; Iivari, Hirschheim, \& Klein, 1998; Orlikowski \& Baroudi, 1991). Tashakkori and Teddlie (1998) described this positivist polarity as "paradigm wars" between the positivists and anti-positivists. While we do not perceive positivism to be at war with aesthetics, scientists in general demonstrate discomfort with its non-scientific underpinnings, such as subjectivity, ambiguity, and emotion. Schaeffer (1976) suggested that the consistency with which individuals apply the tenets of positivism to their lives often results in a pervasive world view, a positivist lens through which individuals view their environment. "People have presuppositions, and they will live more consistently on the basis of those presuppositions than even they themselves may realize. By presuppositions we mean the basic way an individual looks at life, his basic world view, the grid through which he views the world. ... Presuppositions also provide a basis for their value and therefore the basis for their decisions" (Schaeffer, 1976, p. 19). An individual who ascribes to positivism in one area of their lives will be influenced by positivism in the other areas. IS researchers who are accustomed to examining phenomena from a positivistic perspective thus may become predisposed to overlooking alternative paradigms, such as aesthetics.

\section{The IS Identity, the Pillars of Positivism, and Positivist Lensing}

Two possible reasons have led to the current focus of IS: 1) IS' pursuance of a distinct organizational identity and 2) IS' interest in the information technology (IT) artifact (those things that are directly related to IS and its identity). Benbasat and Zmud (2003) argued that IS needs a strong identity to survive and to distinguish itself from related disciplines. They reasoned that a discipline establishes its identity both through its boundaries and its research core that defines those boundaries. Taking an opposing view, Agarwal and Lucas (2005) cautioned that an exclusive focus could limit the perceived relevance of IS and negatively affect IS' ability to survive. Others found general agreement across the IS literature that IS research remains focused on how individuals, groups, and organizations interact with information technologies (Sidorova et al., 2008). These authors did observe a broadening of the literature to include web-based research since 2000 , but all of the research that they examined continues to be function-oriented, to the exclusion of aesthetics. Therefore, positivism remains both preeminent in IS research and directly linked with the identity of the IS discipline. The scientific, functional approach of positivism appears to influence the world view of IS researchers, who, despite the importance of visualization in systems development, have thus far excluded aesthetics and visual aesthetic design from the IS literature. We attribute this exclusion to the influence of positivist lensing.

Positivist lensing, namely, viewing the world through positivist presuppositions, provides an explanation for the absence of visual aesthetics from past IS literature in general, and web-based 
research and development in particular. One reason for lensing is that the evolution of computer technologies was motivated by functional objectives. "[S]ince the first computers were not consumer products, their form followed function, and their function did not require anything beyond the basic configuration to do the job" (O. Edwards, 1998, p. 131). Secondly, as long as the functional systems needs have been fulfilled, visual appearance in systems interfaces has been considered circumstantial. "IT applications are about finance, about accounting, about making money. They are not about impressing anyone. They are designed to work well" (Goff, 1998, p. 5). Because of this predominating functional view of technologies (Sidorova et al., 2008), IS researchers either may fail to see a connection between aesthetics and IS or they may incorrectly apply positivist approaches to aesthetics.

To illustrate positivist lensing of things that are aesthetic, we employ the "five pillars of positivism" (Goles \& Hirschheim, 2000), which itemizes the scientific method with its major supporting philosophies and tools of the positivist system. In the first column of Table 1 we list each of the five pillars. In the adjacent column we list a corresponding, consistent view of aesthetics through a positivist lens (Schaeffer, 1976). We show that if positivism is consistently applied to nonpositivist disciplines (e.g., aesthetics and visual aesthetic design), the lensing effect can be distorting.

The first pillar, and the cornerstone of positivist inquiry, (Goles \& Hirschheim, 2000) is the scientific method. According to Merriam-Webster ("Scientific method," 2010), the scientific method is "principles and procedures for the systematic pursuit of knowledge involving the recognition and formulation of a problem, the collection of data through observation and experiment, and the formulation and testing of hypotheses." Positivism deems the method as valid for all forms of inquiry, including aesthetic problems, testing of aesthetic theories, and other alternative forms of inquiry, including those used by aestheticians and artists. Viewing other disciplines through a positivist lens, the scientific method trumps alternative non-scientific inquiries.

\begin{tabular}{|l|l|l|}
\hline \multicolumn{3}{|c|}{ Table 1: A lensed comparison of the philosophies of positivism and aesthetics } \\
\hline & $\begin{array}{l}\text { The Five Pillars of Positivism } \\
\text { (Goles and Hirschheim, 2000) }\end{array}$ & $\begin{array}{l}\text { Aesthetics Viewed through a Positivist Lens } \\
\text { (after Schaeffer, 1976) }\end{array}$ \\
\hline $\mathbf{1}$ & $\begin{array}{l}\text { Scientific method - the method is } \\
\text { valid for all forms of inquiry }\end{array}$ & $\begin{array}{l}\text { The scientific method is valid for resolving aesthetic prob- } \\
\text { lems and testing aesthetic theories; alternative forms of } \\
\text { inquiry-including those used by aestheticians and art- } \\
\text { ists-are not scientific and therefore unnecessary }\end{array}$ \\
\hline $\mathbf{2}$ & $\begin{array}{l}\text { Reductionism - everything is re- } \\
\text { ducible into smaller and smaller } \\
\text { parts }\end{array}$ & $\begin{array}{l}\text { Fine painting is pigment applied to canvas, music is dis- } \\
\text { turbed molecules in the air, emotion is chemical processes } \\
\text { in the brain, religious beliefs are unfounded }\end{array}$ \\
\hline $\mathbf{3}$ & $\begin{array}{l}\text { Empiricism - only data experienced } \\
\text { with the senses is valid }\end{array}$ & $\begin{array}{l}\text { Attitudes of art and beauty are outcomes of habit and envi- } \\
\text { ronment, resulting from accumulated experience }\end{array}$ \\
\hline $\mathbf{4}$ & $\begin{array}{l}\text { Science and its process are value- } \\
\text { free, and transcend all cultural and } \\
\text { social beliefs }\end{array}$ & $\begin{array}{l}\text { Art and beauty, not being scientific, are without inherent } \\
\text { value and cannot be judged to be good or bad }\end{array}$ \\
\hline $\mathbf{5}$ & $\begin{array}{l}\text { Logic and mathematics - the tools } \\
\text { of science }\end{array}$ & $\begin{array}{l}\text { Art and beauty only can be quantified or understood } \\
\text { through logic and reason; emotion and enjoyment without } \\
\text { scientific explanation are irrelevant }\end{array}$ \\
\hline
\end{tabular}


The second pillar is reductionism. Reductionism states that a physical system is equal to the sum of its parts and that one gains knowledge of a system by extracting and studying its component parts (Runes, 1977). Lensing other disciplines, this assertion leads to the conclusion that synergies in relationships, commerce, or nature are not possible. Lensed through reductionism, fine painting becomes pigment applied to canvas, trivializing the great works of Rembrandt, Rafael, and Monet. Music becomes disturbed molecules in the air, minimizing the symphonies of Beethoven and Brahms. Emotion becomes chemical processes in the brain, debunking the universal human experience of love and with it the poetry of Byron, Shelly and Keats. Religious beliefs become unfounded superstition, emphatically rejecting a major source of spiritual significance for over 80 percent of the 6 billion individuals worldwide (Adherents, 2005).

The third pillar is empiricism. Empiricism, a philosophical subset of epistemology, states that knowledge arises from sensory experience. Empiricism is a key part of the scientific method, asserting that only data experienced with the senses is valid. Thus, theories must be tested against results observed in the natural world (Runes, 1977). By lensing aesthetics though empiricism, attitudes of art and beauty are learned. They are outcomes of habit and environment, resulting from accumulated experience. Applying this lensed approach to web-based design, IS designers will base their visualizations on other designs whose characteristics are accumulated from designs previously deemed acceptable, rather than applying sound aesthetic design theory. Creativity withers, as it is diametric to empiricism.

The fourth pillar of positivism is the assertion that science and its process are value-free. Science is neither good nor bad, but produces results uninfluenced by personal beliefs. It transcends all cultural and social beliefs (Runes, 1977). Technology is an application of science. Viewed through a positivist lens, art and beauty are devoid of inherent value and cannot be judged to be good or bad. Applying this approach to web-based design, IS designers will find all visualizations to be equivalent, with website value determined solely by the site's functional characteristics. In other words, through the lens there exists no visual system concept of "attractive."

The fifth and final pillar of positivism is the toolset of science: logic and mathematics. Solutions in a positivist system are obtained quantitatively, rather than qualitatively (Runes, 1977). Viewed through the lens, art and beauty only can be quantified or understood through logic and reason. Emotion and enjoyment without scientific explanation are not meaningful. Applying this approach to web-based design, IS designers will fail to consider adequately the emotional response (the affect) elicited by visualizations, with website effect determined solely by the site's objectively measurable characteristics. Emotion, which is the primary purpose of art and a primary force that influences user behavior in aesthetic design, is not considered thorough the positivist lens.

Goles and Hirshheim (2000) are not alone; other authors have sought to characterize IS in the context of science (Denning, 2007; Denning \& Freeman, 2009), but despite calls for the expanding of information technology beyond the positivist paradigm (Hirschheim \& Klein, 1989; Hirschheim, Klein, \& Lyytenin, 1995; Iivari et al., 1998; Orlikowski \& Baroudi, 1991; Tractinsky et al., 2006; Walsham, 1995) aesthetics is overlooked. Despite calls from the related discipline of $\mathrm{HCI}$ to expand information technology to embrace aesthetics and visual design theory (Cai, $\mathrm{Yu}$, \& Xu, 2008; De Angeli et al., 2006; Hartmann et al., 2008; Hassenzahl, 2004; Lavie \& Tractinsky, 2004), neither aesthetics nor visual design has made significant inroads into IS theory or practice.

\section{The Positive Influence of Product Aesthetics}

Properly utilized, aesthetics plays a significant role in the design of consumer products, because aesthetic impression is associated with a product halo effect that influences consumer perceptions 
of other design features (Tractinsky et al., 2000). Marketing research demonstrated that aesthetics is relevant to all products, regardless of function (Holbrook \& Zirlin, 1985) and that consumers purchase the product that they perceive to be more aesthetically attractive, when given the choice between two products of identical price and function (Kotler \& Rath, 1984; Nussbaum, 1988). Advertising research has shown that quality photorealistic images communicate to the consumer in much the same way as the physical product does. The association between aesthetics and overall impression leads to the recommendation that product designers, sales people, and ecommerce/website designers should understand both the appropriate techniques and the limitations of product representation throughout the product design, development, and marketing processes (Artacho-Ramirez et al., 2008). "The physical form or design of a product is an unquestioned determinant of its marketplace success. A good design attracts consumers to a product, communicates to them, and adds value to the product by increasing the quality of the usage experiences associated with it" (Bloch, 1995, p. 16).

\section{Adding Visual Design to the Systems Development Product}

Although aesthetics is paradigmatically dissimilar from functional IS theory, we propose that systems theory be enlarged to embrace visual aesthetic design because virtually all users now use visual interfaces. Although the challenge of IS now embracing multiple paradigms is significant, consumer research indicates the users have already crossed that threshold and IS has fallen behind.

As indicated in Figure 1, many reference disciplines currently are used in the systems development process. All of these systems contain a visual interface. Yet positivist lensing precludes control of the aesthetic visual characteristics. We contend that the systems design still impacts the user, regardless of the intention of the systems designer. Lensing the visual systems requirements so that the IS developer lessens his/her knowledge and control of the visual system can make the resultant system much less effective. Figure 2 proposes that the missing aesthetic visual elements be inserted into the IS design process.

Aesthetic thought predates science. It is an aesthetic article of faith that people exhibit a fundamental preference for all things beautiful. Not just the beauty of personal appearance, but also that of nature, music, painting, sculpture, architecture, literature, poetry, and theater (Beryls \& Lopes, 2006; Copleston, 1962; Graham, 2003; Hofstadter \& Kuhns, 1976; Runes, 1977). While it is feasible to study aesthetic concepts scientifically, neither the existence nor the significance nor the characteristics of aesthetics depends on scientific test results. Taking a pluralistic view, aesthetic precepts are philosophically independent of science, but are detectable through scientific measurement. The importance of such measurement is that it can add to the scientific understanding of aesthetic phenomena. However, aesthetics is much more than what can be studied "scientifically." When aesthetic characteristics are examined with a positivistic view there is value in considering the native aesthetic context. 

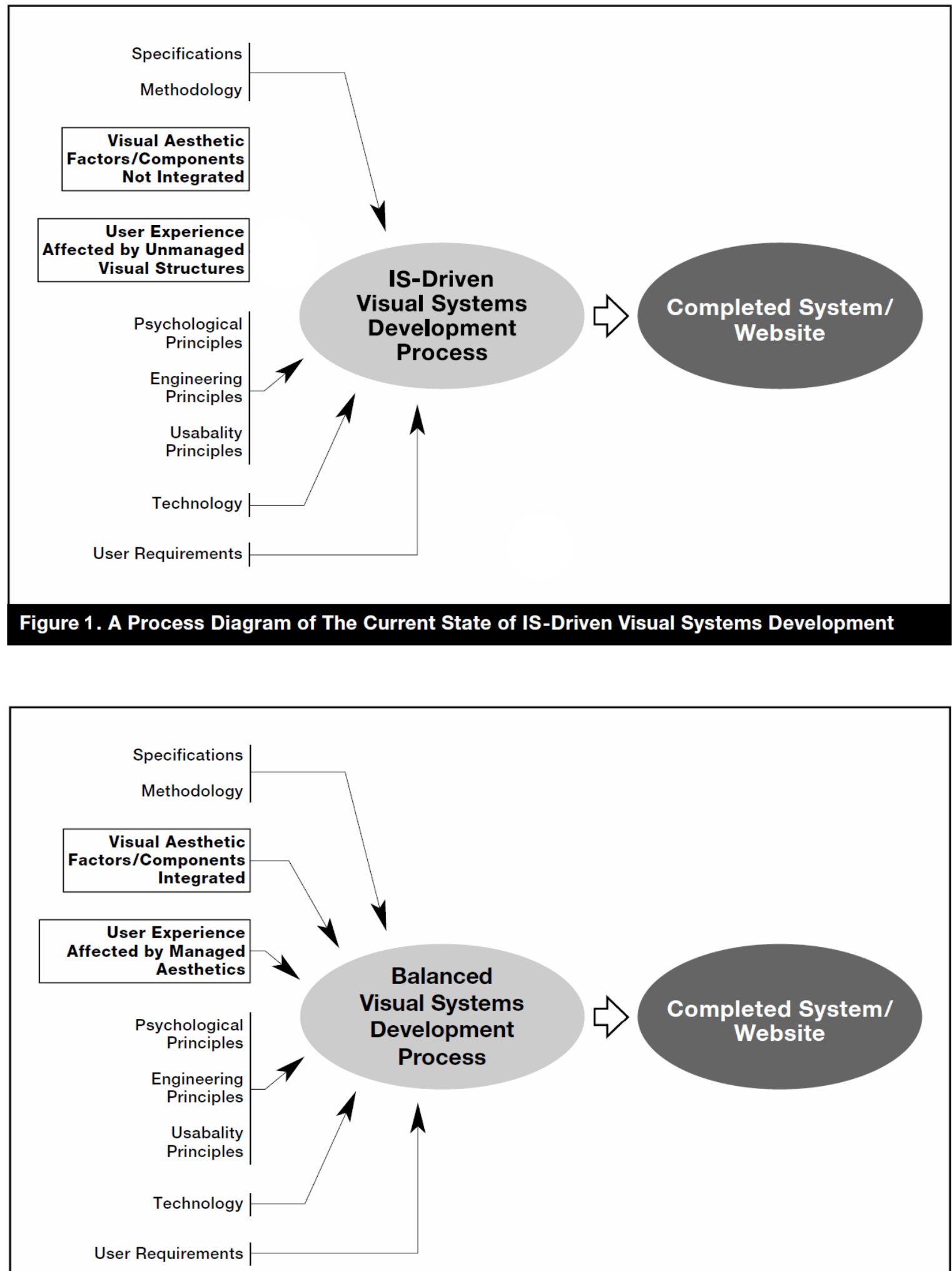

Figure 2. A Process Diagram of a Balanced Approach to Visual Systems Development 
Aesthetic design and its effects are consistently viewed from a positivist perspective in IS literature, despite the fact that many websites are created by visual design methods that can be perceived by the general public (Tractinsky et al., 2006). Historically, aesthetics has often been separated from positivist inquiry. However, as the explosive growth of the number of websites and website users continues, we believe that maintaining this unbalanced perspective may become a detriment to some areas of IS research. The large number of aesthetic design variables that can affect webpage perceptions is worthy of consideration by IS researchers and developers, if only to allow them to make effective use of the information that is gleaned from the websites (Peak et al., in press). Furthermore, since virtually all computer systems have a central visual component, visual aesthetics should be considered for all systems. Above and beyond the functional aspects of systems, understanding and mastery of aesthetic design can provide IS researchers and developers with a viable means to gain greater control over specific website outcomes. Lastly, gaining usable knowledge and experience of aesthetics provides an avenue into human enrichment. The purpose of this research is to begin the closure of the paradigmatically-separated areas of aesthetics and positivism in IS research.

\section{A Visual Systems Development (VSD) Framework Example}

As an example of closing the paradigm gap between aesthetics and positivism, we describe a framework of Visual Systems Development (VSD) borrowed from Peak, Gibson, and Prybutok (in press) and provide an example of the inter-paradigmatic flow of concepts between the aesthetically-oriented visual design and the positivistically-oriented systems development. The VSD process integrates visual aesthetics factors and user experience and owner value outcomes (Figure 3).

At the core of the framework is an inter-paradigm transition zone, which connects the ambiguous and subjectively-oriented aesthetic design paradigm, containing three ordered visual design dimensions, with the more precise and objectively-oriented positivist IT systems development paradigm, containing three ordered IT systems development dimensions (Figure 3). The three aesthetic dimensions of the VSD framework are fundamental premises of the visual design discipline and well-established in that literature: elements of visual design, principles of visual design, and factors of visual composition. The three positivist dimensions are premises of IT systems development: factors of visual systems development, user experience outcomes, and owner value outcomes.

The design of a balanced visual system relies on free, effortless, bi-directional flows of concepts within the VSD framework. We number the dimensions from 1 to 6 , beginning with the dimension at the left end of the framework, the elements of visual design (dimension 1, or D1), and ending at the right end of the framework, with the owner value outcomes (D6). We first note that the terms "elements," "principles," and "compositional factors" are native to aesthetic design, and used by artists and designers operating to identify the ordered, interactive, and often multiplicative characteristics of visual design. Similarly, the terms "construct," "dimension," and "variable" originate from positivist approaches and are used by IT researchers to develop theories and test hypotheses using the scientific method. While these two sets of terms evolved separately, in the framework they can be connected. Retaining the native aesthetic terminology (D1-D3), we also use the positivist terms "construct," "dimension," and "variable" to describe aesthetic characteristics. This provides a common language bridge between the two paradigms, as well as the visual design and IT disciplines. 
Integrating the Visual Design Discipline

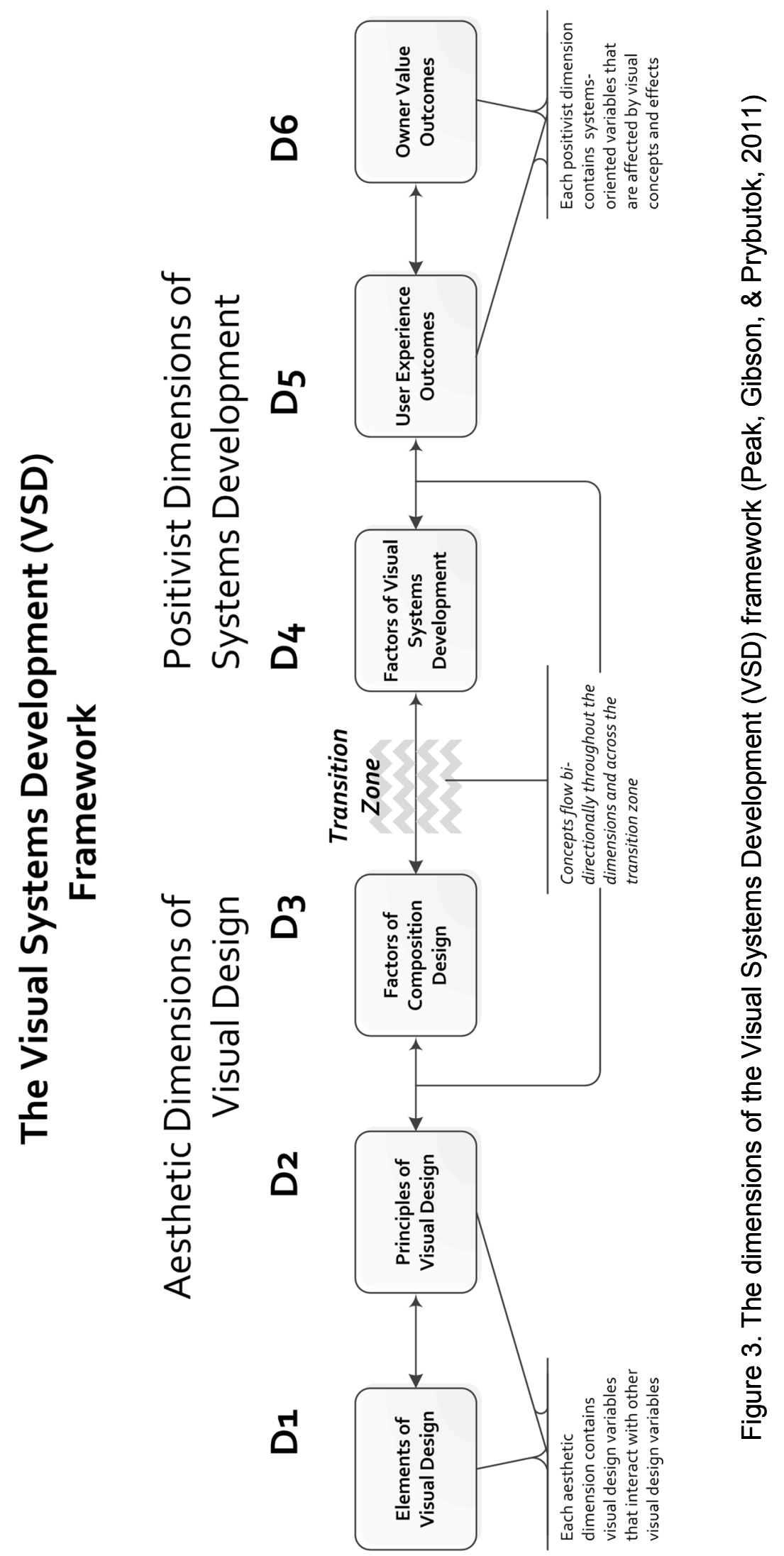


Peak, Prybutok, Wu, \& Xu

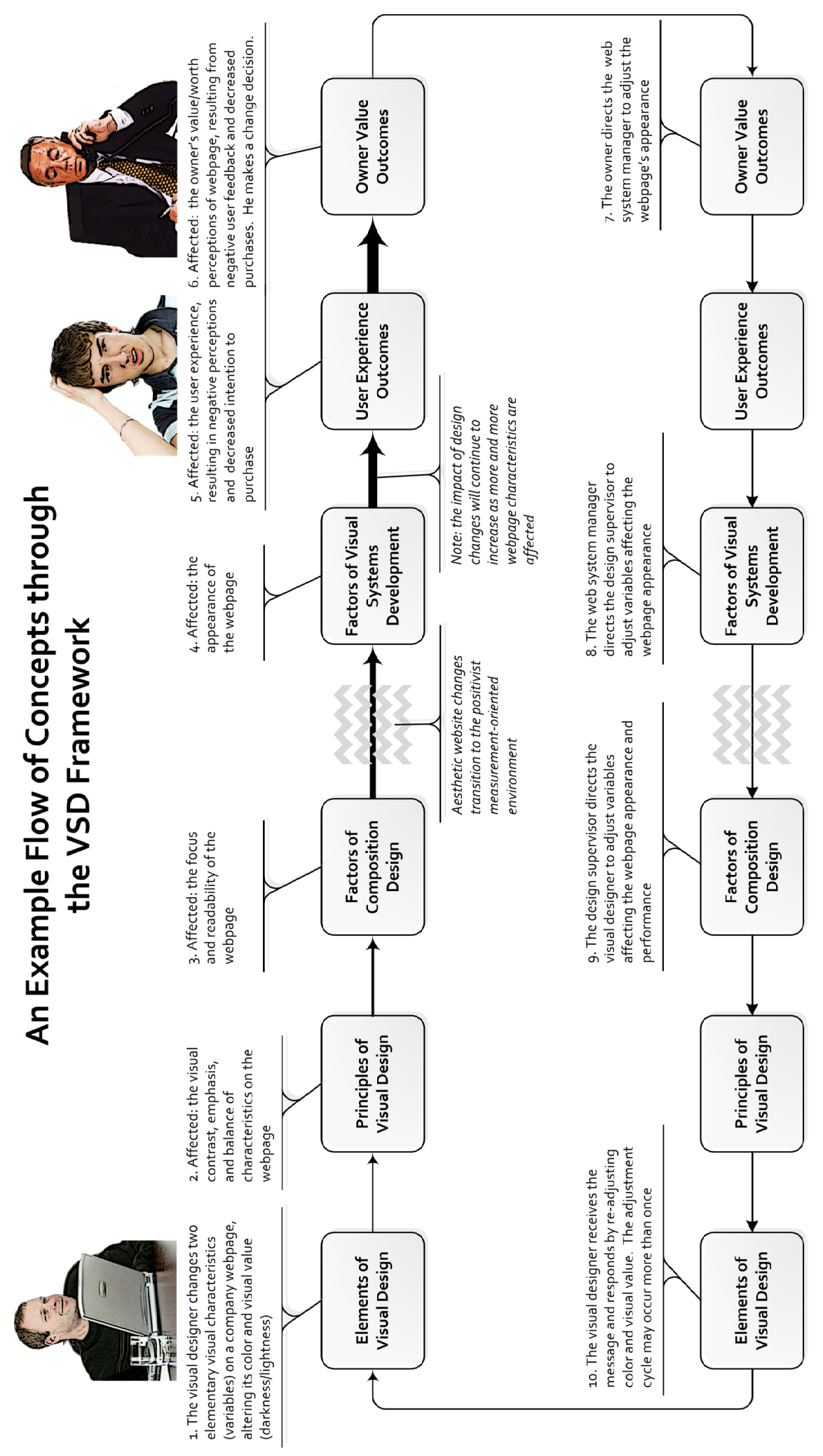

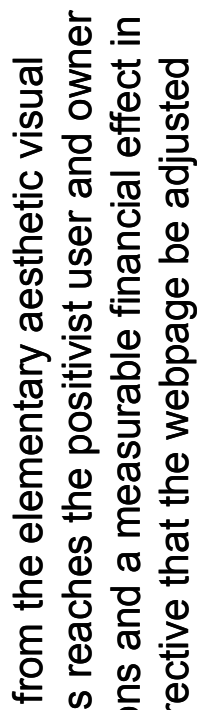

임혹 은 흥

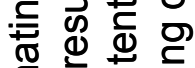

言

응

응

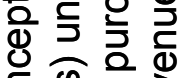

당 ฏ

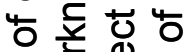

3 증 㐘

象

은등 응 음

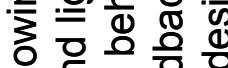

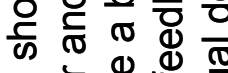

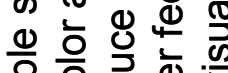

을흥 흥 㐫

ॠ

(

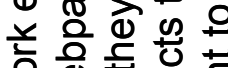

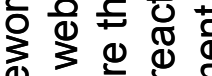

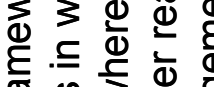

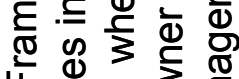

击

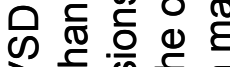

>

ष ठ

믈 흥

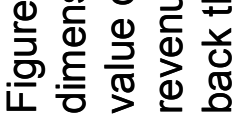


Having introduced the VSD framework, we will next describe a flow of concepts through it, focusing on how the effects of manipulated aesthetic elements can bridge the transition zone and be detected in positivist appearance (D4), which may affect user experience (D5), which in turn may impact the system value (D6) perceptions of the owner (Figure 4). Concepts (information, especially visual information) flow between framework dimensions from left to right (from D1 to D6), and would occur if a visual designer manipulates a webpage using the D1 elements of aesthetic visual value (lightness or darkness) and color (hue and chroma) to influence user perceptions and behavior. The independent variables, elements of design (D1) aesthetic value and color, are manipulated and produce a ripple of ordered effects on intermediate dependent variables through successive levels of the framework (D2-D6). Dependent variables affected are contrast, emphasis, and balance (aesthetic principles of design, D2), focus and readability (factors of compositional design, D3), appearance (a positivist factor of IT website development, D4), user experience (positivist outcome variable, D5) and system value (positivist outcome variable, D6). Because the starting location of this visual change is outside the realm of traditional IT systems design methodology, we believe it advisable that both IT systems developers and researchers acquire a basic aesthetic understanding of all the affected terms. The variables' combined and often multiplicative effects strongly influence the user experience outcome and subsequently the system value.

Concept flows between framework dimensions in the opposite direction (from D6 to D1) would also occur if the system owner (D6) were to determine, based on concept flows from user experience (D5) system feedback, that the webpage colors or values were unacceptable for any reason in various dimensions. One reason might be that the user perceived the webpage's appearance (D4) to be unsatisfactory, perhaps because of its poor readability or deficient visual focus (D3). The appearance and readability may have been adversely affected by the poor value contrast or misplaced emphasis on textual characteristics, or even the poor color balance of background images and foreground text (D2). To correct the perceived webpage inadequacies, the designer would be instructed by the owner, through the appropriate channels of the organization. The designer would iteratively adjust the aesthetic value and color (D1) on the webpage to achieve the directed result. The change process would also affect other intermediate dependent variables and ultimately increase the economic system value (D6) of the webpage to its owner. The system owner would evaluate the system value primarily using positivist financial and technical measures, while the visual designer would manipulate aesthetic value and color based on sound aesthetic practice and theory. However, the system owner would exercise subjective assessment, as well. Both the subjective and objective ways of managing the integrated developmental processes and associated dialogue would be contained in the common methodology bridge. Ideally, the free flow of concepts throughout the framework is effortless and bi-directional, leading to an optimal Visual Systems Design. The aforementioned recursive process (shown in Figure 4), with a focus on integrating the aesthetics and IS paradigms, represents an incarnation of our balanced approach to visual systems development.

\section{Conclusion}

Aesthetics and its visual characteristics, as part of the aesthetic paradigm, were developed and refined by the artistic and design communities over many centuries. At its core, aesthetics is concerned with better understanding and applying theory that guides the creation of beauty, including the sensory beauty and the visual language engendered by a pleasing computer system interface. The current era of graphic interface computing beseeches us to reconsider the influence of interface aesthetics on users and its related societal impact.

This work provides a foundation for future research and development of computer interface design, including website design, to expand to meet the pluralistic challenges of a sensory user 
community. It calls for a pluralistic, transdisciplinary solution that integrates shared wisdom of visual design and IS into a shared foundation of knowledge and practice. Such an approach crosses philosophical and disciplinary boundaries that can impede the flow of knowledge. We believe that harmonious interfaces will provide a better user experience, communicate better, and better accommodate user needs for aesthetic stimulation and functional productivity.

\section{References}

Adherents.com (2005, August 28). Major religions of the world ranked by number of adherents. Retrieved from http://www.adherents.com/Religions By Adherents.html

Agarwal, R., \& Lucas Jr., H. C. (2005). The information systems identity crisis: Focusing on high-visibility and high-impact research. MIS Quarterly, 29(3), 381-398.

Agrawala, M., Li, W., \& Berthouzoz, F. (2011). Design principles for visual communication. Communications of the ACM, 54(4), 60-69.

Artacho-Ramirez, M., Diego-Mas, J., \& Alcaide-Marzal, J. (2008). Influence of the mode of graphical representation on the perception of product aesthetic and emotional features: An exploratory study. International Journal of Industrial Ergonomics, 38, 942-952.

Babad, E., Inbar, J., \& Rosenthal, R. (1982). Teachers' judgment of students' potential as a function of teachers' susceptibility to biasing information. Journal of Personality and Social Psychology, 42, 541547.

Benbasat, I., \& Zmud, R. (2003). The identity crisis within the IS discipline: Defining and communicating the discipline's core properties. MIS Quarterly, 27(2), 183-194.

Berlyne, D. (1974). The new experimental aesthetics. In D. Berlyne, Studies in the new experimental aesthetics (pp. 1-26). New York: Hemisphere Publishing.

Beryls, G., \& Lopes, D. (Eds.) (2006). The Routledge companion to aesthetics. London and New York: Routledge, Taylor \& Francis.

Betz, B., Crockett, T., Davis, J., \& Sparacino, F. (2004). Building a bridge to the aesthetic experience: Artistic virtual environments. SIGGRAPH2004. Retrieved September 13, 2011 from http://delivery.acm.org/10.1145/1190000/1186555/p1eber.pdf?ip $=129.120 .17 .25 \&$ CFID $=41785408 \&$ CFTOKEN $=44282868 \& \quad$ acm $\quad=1315945770 \_4 \mathrm{f} 74 \mathrm{~d}$ 4011d27b0d36f677fc2df1bd4ed

Birkoff, G. (1933). Aesthetic measure. Cambridge, MA: Harvard University Press.

Bloch, P. (1995). Seeking the ideal form: Product design and consumer response. Journal of Marketing, 59(3), 15-29.

Cai, S., Xu, Y., \& Yu, J. (2008). The effects of web site aesthetics and shopping task on consumer online purchasing behavior. CHI 2008 Proceedings, (pp. 3477-3483). Florence, Italy.

Cohen, E. B. (2009). A philosophy of informing science. Informing Science: the International Journal of an Emerging Transdiscipline, 12, 1-15. Retrieved from http://www.inform.nu/Articles/Vol12/ISJv12p001-015Cohen399.pdf

Copleston, F. S. (1962). A history of philosophy: Greece and Rome (New Revised ed., Vol. I Part I). Garden City, New York: Image Books, A Division of Doubleday and Co.

Cowley, G. (2000). The biology of beauty. In W. Lesko (Ed.), Readings in social psychology: General, classic, and contemporary selections (4th ed., pp. 188-194). Boston: Allya and Bacon.

Cyr, D., Head, M., \& Lario, H. (2010). Colour appeal in website design within and acrosscultures: A multimethod evaluation. International Journal of Human-Computer Studies, 68(1-2), 1-21.

Cyr, D., Head, M., Larios, H., \& Bing, P. (2009). Exploring human images in website design: A multimethod approach. MIS Quarterly, 33(3), 539-566. 
Integrating the Visual Design Discipline

De Angeli, A., Sutcliffe, A., \& Hartmann, J. (2006). Interaction, usability and aesthetics: What influences users' preferences? Proceedings of the 6th ACM Conference on Designing Interactive Systems: DIS 2006, (pp. 271-280). University Park, PA, USA.

Denning, P. (2007). Computing is a natural science. Communications of the ACM, 50(7), 15-18.

Denning, P., \& Freeman, P. (2009). The profession of IT computing's paradigm. Communications of the $A C M, 52(12), 28-30$.

Dion, K., Berscheid, E., \& Walster, E. (1972). What is beautiful is good. Journal of Personality and Social Psychology, 24(3), 286-290.

Edwards, D. (2003). The handbook of art and design terms. Upper Saddle River, New Jersey: Pearson, Prentice Hall.

Edwards, O. (1998). Beauty and the box. Forbes, 162(7), 131-132.

Fechner, G. T. (1876). Vorschule der Aesthetik [Introduction to aesthetics]. Leipzig: Breitkopf and Harterl.

Fransworth, P. R. (1932). Preferences for rectangles. Journal of General Psychology, 7, 479-481.

French, M. T. (2002). Physical appearance and earnings: Further evidence. Applied Economics, 34, 569572.

Gill, T. G., \& Bhattacherjee, A. (2007). The informing sciences at a crossroads: The role of the client. Informing Science: the International Journal of an Emerging Transdiscipline, 10, 17-39. Retreived from http://www.inform.nu/Articles/Vol10/ISJv10p017-039Gill317.pdf

Gill, T. G., \& Hevner, A. R. (2011). A fitness-utility model for design science research. Lecture Notes in Computer Science, 6629, 237-252.

Gioia, D., \& Pitre, E. (1990). Multiparadigm perspectives on theory building. Academy of Management Review, 15(4), 584-602.

Goff, L. (1998). Form follows function. Computerworld, 32(43), 1-16.

Goles, T., \& Hirschheim, R. (2000). The paradigm is dead, the paradigm is dead. . long live the paradigm: The legacy of Burrell and Morgan. Omega , 28, 249-268.

Graham, G. (2003). Philosophy of the arts: An introduction to aesthetics (3rd ed.). London and New York: Routledge, Taylor and Francis Group.

Granger, G. W. (1955). An experimental study of color harmony. Journal of General Psychology, 52, 2135 .

Hallnas, L., \& Redstrom, J. (2002). From use to presence: On the expressions and aesthetics of everyday computational things. ACM Transactions on Computer-Human Interaction, 9(2), 106-124.

Hamermesh, D., \& Parker, A. (2005). Beauty in the classroom: Instructors' pulchritude and putative pedagogical productivity. Economics of Education Review, 24, 369-376.

Hartmann, J., Sutcliffe, A., \& De Angeli, A. (2008). Towards a theory of user judgment of aesthetics and user interface quality. ACM Transactions on Computer-Human Interaction, 15(4), 15-30.

Hassanein, K., \& Head, M. (2007). Manipulating perceived social presence through the web interface and its impact on attitude towards online shopping. International Journal of Human-Computer Studies, 65, 689-708.

Hassenzahl, M. (2004). The interplay of beauty, goodness, and usability in interactive products. HumanComputer Interaction, 19(4), 319-349.

Hassenzahl, M., Schöbel, M., \& Trautmann, T. (2008). How motivational orientation influences the evaluation and choice of hedonic and pragmatic interactive products: the role of regulatory focus. Interacting with Computers, 20, 473-479.

Heath, M. (2008). Pleasure in Aristotle's aesthetics. Technosophia. 
Heinrich, F. (2007). The aesthetics of interactive artifacts: Thoughts on preformative beauty. Proceedings of the 2nd International Conference on Digital Interactive Media in Entertainment and Arts (DIMEA '07), 274, pp. 58-64. New York, NY, USA.

Hirschheim, R., \& Klein, H. (1989). Four paradigms of information systems development. Communications of the ACM, 32(10), 1199-1216.

Hirschheim, R., Klein, H., \& Lyytenin, K. (1995). Information systems development and data modeling: Conceptual and philosophical foundations. Cambridge, U.K.: Cambridge University Press.

Hofstadter, A., \& Kuhns, R. (Eds.). (1976). Philosophies of art and beauty: Selected readings in aesthetics from Plato to Heidegger. Chicago, Illinois: University of Chicago Press.

Holbrook, M., \& Zirlin, R. (1985). Artistic creation, artworks, and aesthetic appreciation. Advances in NonProfit Marketing, 1(1), 1-54.

Iivari, J., Hirschheim, R., \& Klein, H. (1998). A paradigmatic analysis contrasting information systems development approaches and methodologies. Information Systems Research, 9(2), 164-193.

Kogan, N. (1994). On aesthetics and its origins: Some psychobiological and evolutionary considerations. Social Research, 61, 139-165.

Kogan, N. (1997). Reflection on aesthetics and evolution. Critical Review, 11, 193-210.

Kolakowski, L. (1968). The alienation of reason: A history of positivist thought. Garden City, New Jersy: Doubleday.

Kotler, P., \& Rath, G. (1984). Design: A powerful but neglected strategic tool. Journal of Business Strategy, 5(2), 16-21.

Krug, S. (2006). Don't make me think: A common sense approach to web usability (2nd ed.). Berkeley, California: New Riders Publishers.

Kuhn, T. (1970). The structure of scientific revolutions. Chicago: University of Chicago Press.

Lavie, T., \& Tractinsky, N. (2004). Assessing dimensions of perceived visual aesthetics of web sites. International Journal of Human-Computer Studies, 60 (3), 269-299.

Lawrence, D., Tavakol, \& Soyhela. (2007). Balanced website design: Optimizing aesthetics, usability, and purpose. London: Springer-Verlag.

Liu, L. (2003). Engineering aesthetics and aesthetic ergonomics: Theoretical foundations and a dualprocess research methodology. Ergononics, 46(13/14), 1273-1292.

Lowe, D., \& Eklund, J. (2001). Development issues in specification of web systems. 6th Australian Workshop on Requirements Engineering, (pp. 4-13). Sidney.

Martindale, C., \& Moore, K. (1988). Priming, prototypicality, and preference. Journal of Experimental Psychology: Human Perception and Performance, 14(4), 661-670.

Moshagen, M., \& Thielsch, M. T. (2010). Facets of visual aesthetics. International Journal of HumanComputer Studies, 68(10), 689-709.

Mullet, K., \& Sano, D. (1995). Desiging visual interfaces: Communication oriented techniques. Upper Saddle River, New Jersy: Pearson, Prentice Hall.

Nadkarni, S., \& Gupta, R. (2007). A task-based model of perceived website complexity. MIS Quarterly, $31(3), 501-524$.

Noblet, J. (1993). Industrial design: Reflections of a century. Paris: Abbeville Press.

Norman, D. (1998). Invisible computer: Why good products can fail, the personal computer is so complex and information appliances are the solution. Cambridge, MA: MIT Press.

Norman, D. (2002a). Emotion and design: Attractive things work better. Interactions, 9(4), 36-42.

Norman, D. (2002b). The design of everyday things. Cambridge, Massachusetts: Perseus Publishing. 
Integrating the Visual Design Discipline

Norman, D. (2004). Emotional design: Why we love (or hate) everyday things. New York: Basic Books.

Nussbaum, B. (1988, April 11). Smart design. Business Week, pp. 102-117.

Orlikowski, W., \& Baroudi, J. (1991). Studying information technology in organizations: Research approaches and assumptions. Information Systems Research, 2(1), 1-28.

Peak, D., Gibson, M., \& Prybutok, V. (in press). Synergizing positivism and aesthetics in the design process of interactive visual systems. Information Design Journal.

Petersen, M., Iversen, O., Krogh, P., \& Ludvigsen, M. (2004). Aesthetic interaction-A pragmatist's aesthetics of interactive systems. Proceedings of DIS2004 (pp. 269-276). Cambridge, Massachusetts: ACM.

Postrel, V. (2002). The substance of style. New York: HarperCollins.

Rand, P. (1993). Design, form, and chaos. New Haven, Connecticut: Yale University Press.

Reber, R., Schwartz, N., \& Winkielman, P. (2004). Processing fluency and aesthetic pleasure: Is beauty in the perceiver's processing experience? Personality and Social Psychology Review, 8(4), 364-382.

Runes, D. (Ed.). (1977). Dictionary of philosophy. Totowa: Littlefield, Adams \& Co.

Russell, B. (1972). A history of western philosophy. New York, New York: Touchstone, Simon and Shuster.

Schaeffer, F. (1976). How should we then live? Old Tappan, New Jersy: Fleming H. Revell Co.

Scientific method. (2010). Retrieved April 15, 2010 from Merriam-Webster Online Dictionary: http://www.merriam-webster.com/dictionary/scientific method

Sheppard, A. (1987). Aesthetics: An introduction to the philosophy of art. Oxford and New York: Oxford University Press.

Shusterman, R. (1992). Pragmatist aesthetics, living beauty, rethinking art. Lantham, Maryland: Rowman \& Littlefield.

Sidorova, A., Evangelopoulos, N., Valacich, J., \& Ramakrishnan, T. (2008). Uncovering the intellectual core of the information systems discipline. MIS Quarterly, 32(3), 467-482.

Tashakkori, A., \& Teddlie, C. (1998). Mixed methodology:Combining qualitative and quantitative approaches. London: Sage.

Tractinsky, N. (2004). Towards the study of aesthetics in information technology. Proceedings of the 25th Annual ICIS (pp. 771-780). Washington, DC.

Tractinsky, N. (2006). Aesthetics in information technology: Motivation and future research directions, Human-Computer Interaction in Management Information Systems: Foundations (pp. 330-347). Armonk, New York: M.E. Sharpe.

Tractinsky, N., Cokhavia, A., Kirschenbauma, M., \& Sharfib, T. (2006). Evaluating the consistency of immediate aesthetic perceptions of web pages. International Journal of Human-Computer Studies, 64(11), 1071-1083.

Tractinsky, N., Katz, A., \& Ikar, D. (2000). What is beautiful is usable. Interacting with Computers, 13, 127-145.

Tractinsky, N., \& Rao, V. (2001). Incorporating social dimensions in web-store design. Human Systems Management, 20 (2), 105-121.

Walsham, G. (1995). The emergence of interpretivism in IS research. Information Systems Research, 6(4), 376-394.

Zhang, P. (2009). Affect and aesthetics in ICT design and use. Proceedings of the International Conference on Information Resource Management. Dubai, United Arab Emirates. 


\section{Biographies}

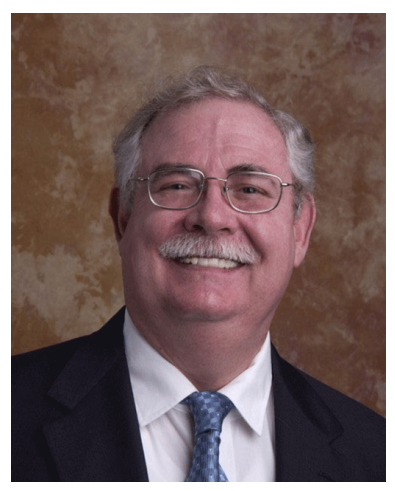

Daniel A. Peak is an associate professor in information technology in the Information Technology and Decision Sciences Department, College of Business Administration at the University of North Texas. He received his Ph.D. in 1994 from UNT with majors in Information Systems and in Finance. He is an editor of the Journal of IT Cases and Applications Research. Dr. Peak has more than 20 years of IT consulting and planning experience working for executives of Fortune 500 companies, and has won and directed numerous production projects and research grants. He is a member of the Decision Science Institute and Association for Information Systems and has publications in Informing Science, Information and Management, Information Systems Management, Journal of Computer Information Systems, and other journals. Dan can be reached by email at peak@unt.edu

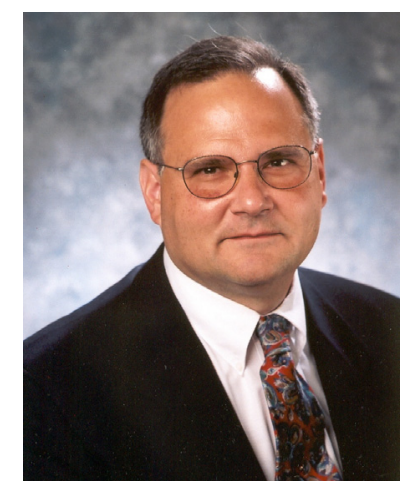

Victor R. Prybutok is a Regents Professor of Decision Sciences in the Information Technology and Decision Sciences Department and Associate Dean of the Toulouse Graduate School at the University of North Texas. He received, from Drexel University, his B.S. with High Honors in 1974, a M.S. in Bio-Mathematics in 1976, a M.S. in Environmental Health in 1980, and a Ph.D. in Environmental Analysis and Applied Statistics in 1984. Dr. Prybutok is an American Society for Quality certified quality engineer, certified quality auditor, certified manager of quality / organizational excellence, and an accredited professional statistician (PSTAT®) by the American Statistical Association. Dr. Prybutok has authored over 100 journal articles, several book chapters, and more than 100 conference presentations in information systems measurement, quality control, risk assessment, and applied statistics.

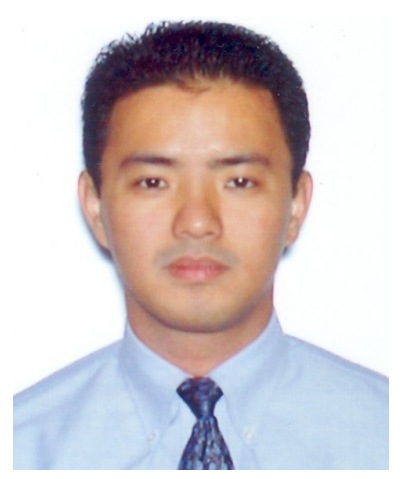

$\mathbf{Y u}$ "Andy" Wu is an assistant professor in the Department of Information Technology and Decision Sciences, College of Business at the University of North Texas. He received a Ph.D. in Management Information Systems from the University of Central Florida, Orlando, FL, in 2007. His primary research interests include social networks and information security. His research papers appeared in international conferences and journals including Informing Science, Journal of Organizational and End User Computing, International Journal of Networking and Virtual Organizations, etc. Before his academic career, Dr. Wu had seven years' experiences in various business and management positions. 


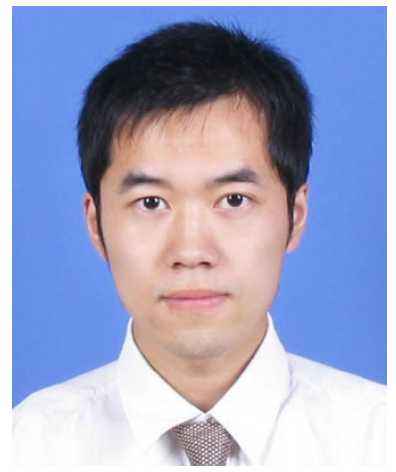

Chenyan Xu is currently a Ph.D. candidate in the Department of Information Technology and Decision Sciences, College of Business, at the University of North Texas. Prior to UNT, he was an auditor in Deloitte Touche Tohmatsu C.P.A. Ltd. (Shanghai). He obtained his bachelor of business administration degree in electronic commerce from the Shanghai Institute of Foreign Trade, China and master of science degree in new media from The Chinese University of Hong Kong, China. His recent research interests include social networking sites, ecommerce, knowledge management, and interface design. 